\title{
TEM investigation on zirconate formation and chromium poisoning in LSM/YSZ cathode
}

\author{
A. Hessler-Wyser $\cdot$ Z. Wuillemin $\cdot$ J. A. Schuler • \\ A. Faes $\cdot$ J. Van herle
}

Received: 15 August 2010/Accepted: 29 January 2011/Published online: 15 February 2011

(C) Springer Science+Business Media, LLC 2011

\begin{abstract}
Cell durability is a crucial technological issue for SOFC commercialization, and considerable progress has been made in recent years. A number of degradation pathways have been established, amongst which microstructural changes, poisoning effects and formation of less conductive phases. In this study, transmission electron microscopy was used to observe submicron-scale effects on selected cathode zones of an anode supported cell tested in SOFC stack repeat element configuration. The test has been performed with a dedicated segmented test bench, at $800{ }^{\circ} \mathrm{C}$ for $1900 \mathrm{~h}$, which allowed to spatially resolve degradation processes, and therefore to improve their correlation with localized post-test analysis. Evidence is presented of reaction products (mainly $\mathrm{SrZrO}_{3}$ ) at the LSM/ YSZ interfaces as well as of contaminants, in particular $\mathrm{Cr}$, but also Si. A polarized cell segment is compared to an unpolarized one, to assess any influence of cathode polarization.
\end{abstract}

This article has been presented as part of the European Materials Research Society E-MRS Spring meeting Symposium Q "Quantitative Electron Microscopy for Research and Industry".

A. Hessler-Wyser $(\bowtie)$ J. A. Schuler · A. Faes Interdisciplinary Centre for Electron Microscopy (CIME), Ecole Polytechnique Fédérale de Lausanne (EPFL),

1015 Lausanne, Switzerland

e-mail: aicha.hessler@epfl.ch

Z. Wuillemin · J. A. Schuler · A. Faes · J. Van herle Industrial Energy Systems Laboratory (LENI),

Ecole Polytechnique Fédérale de Lausanne (EPFL),

1015 Lausanne, Switzerland

\section{Introduction}

Efficient energy conversion is a clear objective for most countries and many efforts are made to reduce energy consumption as well as emissions. Amongst the numerous options, solid oxide fuel cells (SOFC) represent an attractive technology, as they enable to cogenerate electricity and heat with high electrical efficiency (60\%) already for small scale systems $(\mathrm{kW})$. They are considered for decentralised electricity production at small to medium scale and represent a step towards sustainable development. However, systems for stationary applications should reach at least $40,000 \mathrm{~h}$ of operation, which is not the case today mainly because of degradation phenomena occurring at different cell and stack levels.

To ensure high conductivity and efficiency, SOFCs are operated at temperatures from 600 to $1000{ }^{\circ} \mathrm{C}$, which are demanding for their components. Many interactions between component materials occur, which can affect the active sites for the desired electro-chemical reactions. In case of composite materials, the latter take place preferentially at the triple phase boundaries (TPB), the connected zones between the pores for gas transport and the ionic and electronic conductive phases. Several phenomena are known to alter the TPB length, such as grain size modification, secondary phase formation, pollutant species deposition or crack occurrence. Reviews of SOFC degradation mechanisms and material interactions can be found in [1-3].

SOFC cathodes can be made out of different materials, among which the most widely used is a composite of strontium-doped lanthanum manganite (LSM) and yttria stabilized zirconia (YSZ), the latter also being the standard SOFC electrolyte component. The interaction between these two materials has been largely investigated and 
several parameters have been evidenced to influence their interaction mechanisms, such as temperature, oxygen partial pressure, reaction time, polarization (current load) and possible pollution sources. Amongst the features identified to affect the reactivity of cathode components, secondary phase formation [4-8] and $\mathrm{Cr}$ poisoning [9-19] are widely reported.

The influence of temperature has been reported already in 1976 by Baukal et al. [4], who identified $\mathrm{SrZrO}_{3}$ (SZO) formation in $\mathrm{La}_{0.8} \mathrm{Sr}_{0.4} \mathrm{Cr}_{0.8} \mathrm{Ni}_{0.2} \mathrm{O}_{3} / \mathrm{YSZ}$, only above $1250{ }^{\circ} \mathrm{C}$. In 1986, Yamamoto et al. [5] showed that LSM/ YSZ interaction $(30 \% \mathrm{Sr})$ could result in SZO formation, but not below $1100{ }^{\circ} \mathrm{C}$. Stoguchi et al. [20] detected $\mathrm{La}_{2} \mathrm{Zr}_{2} \mathrm{O}_{7}$ (LZO) as reaction product between LSC $\left(\mathrm{LaSrCoO}_{3}\right)$ and $\mathrm{YSZ}$ at $800{ }^{\circ} \mathrm{C}$, and $\mathrm{SZO}$ at 1000 and $1200{ }^{\circ} \mathrm{C}$. No reaction product was observed, however, between LSM and YSZ at $1200{ }^{\circ} \mathrm{C}$. Stochniol et al. [21] found only LZO when annealing LSM/YSZ at 1200 and $1400{ }^{\circ} \mathrm{C}$ for $200 \mathrm{~h}$, for different LSM compositions.

More recently and in similar systems but with different Sr doping of LSM, Cortès et al. [22] carried out a quantitative analysis of secondary phase formation by X-ray diffraction (XRD) and Rietveld refinement after $2 \mathrm{~h}$ of temperature treatments ranging from 1000 to $1400{ }^{\circ} \mathrm{C}$. They showed that SZO was mostly present for LSM with $15 \% \mathrm{Sr}$ for lower temperature, decreasing for higher temperature, contrary to LZO that starts to be visible for $1200{ }^{\circ} \mathrm{C}$ and higher.

Chen et al. [8] mentions the formation of both LZO and $\mathrm{SZO}$ in pellets with initial LSM/YSZ ratio of 25/75 when annealed in $\mathrm{N}_{2}$ at $1000{ }^{\circ} \mathrm{C}$ for 5 weeks, while only SZO could be detected for a LSM/YSZ ratio of 50/50. When annealed in air, no secondary phase was detected. By changing the atmosphere, they could evidence the influence of the oxygen partial pressure, and that the direction of the LSM-YSZ reaction can be reversed, yet not to $100 \%$.

On cells tested at $750{ }^{\circ} \mathrm{C}$ in both air and pure oxygen, Liu et al. [7] could localize LZO at the LSM/YSZ cathode interface with the electrolyte after dissolution of the cathode. They recognized that the presence of SZO cannot be excluded as it might be dissolved together with the cathode. They showed that the chemical stability and degradation process of the cathode/electrolyte interface is strongly affected by the local oxygen activity. They also calculated the critical $p\left(\mathrm{O}_{2}\right)$ for zirconate formation as a function of temperature for such systems, and showed that the risk of zirconate formation is reduced at low current load and high $p\left(\mathrm{O}_{2}\right)$.

One may summarize that most concern in the past was given to formation of LZO and that reaction between LSM and YSZ was mostly detected at temperatures $>=$ $1000{ }^{\circ} \mathrm{C}$; only very recently more attention was drawn also to lower temperatures. Although usually both lanthanum zirconate (LZO) and strontium zirconate (SZO) are mentioned as reaction products, direct identification of SZO is scarce, most of the published research focusing on LZO growth mechanisms and the parameters enhancing or preventing this phase formation.

A second important, widely reported, source of cathode degradation is $\mathrm{Cr}$ poisoning. The source of volatile $\mathrm{Cr}$ species is known to be the Cr oxide scale formed on the surface of the alloys used as metal interconnects $[9,23]$ or as balance-of-plant components [24], after prolonged exposure at elevated temperature, as it is the case during SOFC operation. Depending on the oxygen and/or the water vapour pressures, gas phase transport of $\mathrm{Cr}$ can occur under the form of $\mathrm{CrO}, \mathrm{CrO}_{2}, \mathrm{CrO}_{3}$ or $\mathrm{CrO}_{2}(\mathrm{OH})[9,17$, 23]. The redeposition mechanism of chromium usually as $\mathrm{Cr}_{2} \mathrm{O}_{3}$ is debated and two pathways are found in the literature. While Taniguchi et al. [23] and Badwal et al. [9] link the $\mathrm{Cr}$ poisoning to the electrochemical reduction of gaseous, mainly $\mathrm{Cr}(\mathrm{VI})$, species to solid $\mathrm{Cr}_{2} \mathrm{O}_{3}$ in competition with the oxygen reduction reaction, Jiang et al. [13] claim the deposition to be controlled by chemical dissociation induced by $\mathrm{Mn}^{2+}$ ions interacting with $\mathrm{CrO}_{3}$. However, both hypotheses agree that $\mathrm{Cr}$ contamination is directly linked to cathode polarization, as also shown by other authors [10, 11, 15, 16, 19].

Yokokawa et al. [25] suggest that chromium deposition at the electrode/electrolyte interface is driven by the oxygen potential gradient, caused by the high $\mathrm{Mn}^{4+}$ stability and slow oxygen ion diffusivity in LSM.

Most of the authors who investigated $\mathrm{Cr}$ deposition could localise it at the electrode/electrolyte interface either as $\mathrm{Cr}_{2} \mathrm{O}_{3}$ or as spinel $\mathrm{CrMn}_{2} \mathrm{O}_{4}[9,10,19,25-27]$, the latter being mostly present at the cathode/electrolyte interface whereas $\mathrm{Cr}_{2} \mathrm{O}_{3}$ can be observed everywhere in an LSM cathode $[11,15]$.

Both cathode degradation effects discussed abovezirconate formation and chromium poisoning-have been investigated from a microstructural point of view, mainly by XRD and scanning electron microscopy (SEM) together with energy dispersive X-ray spectroscopy (EDS). Owing to the high-interaction volume, small features cannot be detected by these combined techniques. A few studies have investigated the localization of zirconates and chromiumrich phases at the nanometre scale in the cathode and at the cathode/electrolyte interface. Salvador et al. [28] reported TEM observations of $\mathrm{Cr}_{2} \mathrm{O}_{3}$ and $(\mathrm{CrMn})_{3} \mathrm{O}_{4}$ nanoparticles filling the cathode pores, the former being the main phase at the LSM/YSZ interface. LZO has been observed by transmission electron microscopy (TEM) $[3,6,7]$ either as nanoparticles or as precipitates grown epitaxially with the YSZ grains at the LSM/YSZ grain boundaries. To our knowledge, no evidence of SZO has been shown by TEM.

Previous studies from these authors performed on a segmented SOFC stack repeat element tested over $1900 \mathrm{~h}$ 
showed that pollutant species, mainly located at the air inlet of the cell, were directly related to locally measured degradation $[24,29,30]$. The local degradation of the different electrochemical processes was revealed by a differential analysis of the impedance spectra, which enabled to identify the cathode as mainly degraded electrode. Furthermore, the level of local degradation was correlated to pollutant species at the cathode side $(\mathrm{Cr}, \mathrm{Si}$ and $\mathrm{S})$, affecting principally the oxygen reduction reaction and maybe its diffusion [29]. Furthermore, higher ohmic resistance was observed on the polarized segments of the cell when compared with nonpolarized ones, and finally, differences were observed at high frequency between non-polarized and polarized segments, indicating a possible degradation of the charge transfer reaction between LSM and YSZ on the polarized segments [30]. For both observations, less conductive secondary phases could be responsible for this resistance increase, as well as an alteration of the adhesion between LSM and YSZ grains. Investigation of the cathode at the nanometre scale, with focus on the presence of $\mathrm{Cr}$, zirconate formation and the possible delamination of phases, was thus judged relevant; this article reports results obtained by TEM-EDS on two cathode cross-sections: one extracted from a polarized and one extracted from a non polarized segment, both located at the affected air inlet zone.

\section{Experimental}

The tested cell was a nickel-yttria stabilized zirconia (YSZ) anode support with a few $\mu \mathrm{m}$ thin dense 8YSZ electrolyte, a strontium-doped lanthanum manganite (LSM, La/Sr ratio of 75/25)-8YSZ composite cathode, a strontium-doped lanthanum cobaltite (LSC) current collection layer and a proprietary gas diffusion layer [29]. The interconnect is ferritic steel segmented according to the cathode deposition. The polarization of each of the 18 segments was controlled individually to monitor locally the cell performance and degradation over the operation time. The onecell stack was tested at $800{ }^{\circ} \mathrm{C}$ over $1900 \mathrm{~h}$. Two segments from the air inlet region, which was the most affected, have been selected for SEM and TEM analysis. Details on the segmented device, test conditions and electrochemical results are given in $[29,30]$, together with post-mortem observations performed by SEM + EDS [24]. In order to examine the polarization effect (namely the current load effect) in a region identically exposed to pollutants (air inlet), and as suggested by the typical differences in the recorded impedance spectra mentioned above, one polarized segment was compared with a non-polarized neighbour segment, as shown on Fig. 1 illustrating schematically the segmented cell with the contamination mapping obtained from SEM + EDS analyses [29].

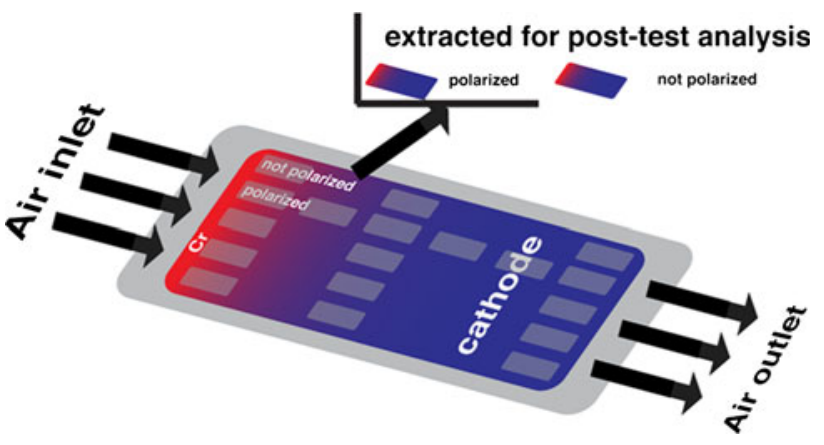

Fig. 1 Segment locations on the cell. Red colour qualitatively indicates the relative $\mathrm{Cr}$ distribution over the current collection surface

Based on the SEM + EDS mapping information obtained on both segment cathode cross-sections, TEM lamellae have been extracted from embedded samples by FIB using a Zeiss NVision 40 Crossbeam, with a final polishing at $1 \mathrm{keV}$, as shown in Fig. 2. The final thickness for both lamellae was between 50 and $100 \mathrm{~nm}$. In the case of the polarized segment, previous studies [24, 29, 30] showed that a high quantity of $\mathrm{Cr}$ was deposited at the collection current layer surface, with a smaller amount of $\mathrm{Cr}$ found at the cathode/electrolyte interface. The TEM lamella has been extracted from one of these latter regions.

TEM analysis has been done with a Philips CM300UT operating at $300 \mathrm{kV}$, in dark-field scanning transmission electron mode (DSTEM), coupled with an Oxford EDS detector controlled by Oxford Inca software. EDS maps were acquired as one single frame for a total acquisition time of $1 \mathrm{~h}$, during which a sample drift occurred. This explains discrepancies between the electron image and the slightly distorted maps, but has no consequences on the results interpretation, as additional point spectra have been acquired to confirm the observed phases. All EDS maps have been acquired with the standard emission lines and background corrected. In EDS spectra, the $\mathrm{Cr} \mathrm{K} \alpha$ and $\mathrm{K} \beta$ lines show an overlap with those from $\mathrm{La}$ and $\mathrm{Mn}$; $\mathrm{Cr}$ detection is not straightforward with this technique [31], therefore energy filtered TEM (EFTEM) has been undertaken to remove this ambiguity on the $\mathrm{Cr}$ detection. The latter was performed on a Jeol 2200 FS equipped with an in-column omega filter.

\section{Results}

The unpolarized cathode segment has been observed by DSTEM, and Fig. 3 gives an overview of the TEM lamella, with the YSZ electrolyte at the bottom and the porous LSM/YSZ cathode on top. In the white square are the regions considered for detailed investigation. The larger and smaller cathode grains are identified by EDS as LSM and YSZ, respectively. 
Fig. 2 SEM micrographs of the TEM lamella lift-out, with superimposed EDS mapping of $\mathrm{Cr}$ in red. Left cross-section of the sample with current collection layer on the left (LSC), cathode in the middle (LSM/YSZ) and electrolyte on the right (YSZ, the dense part of the image). Right TEM lamella after final thinning. The lamella was extracted from the cathode/ electrolyte interface

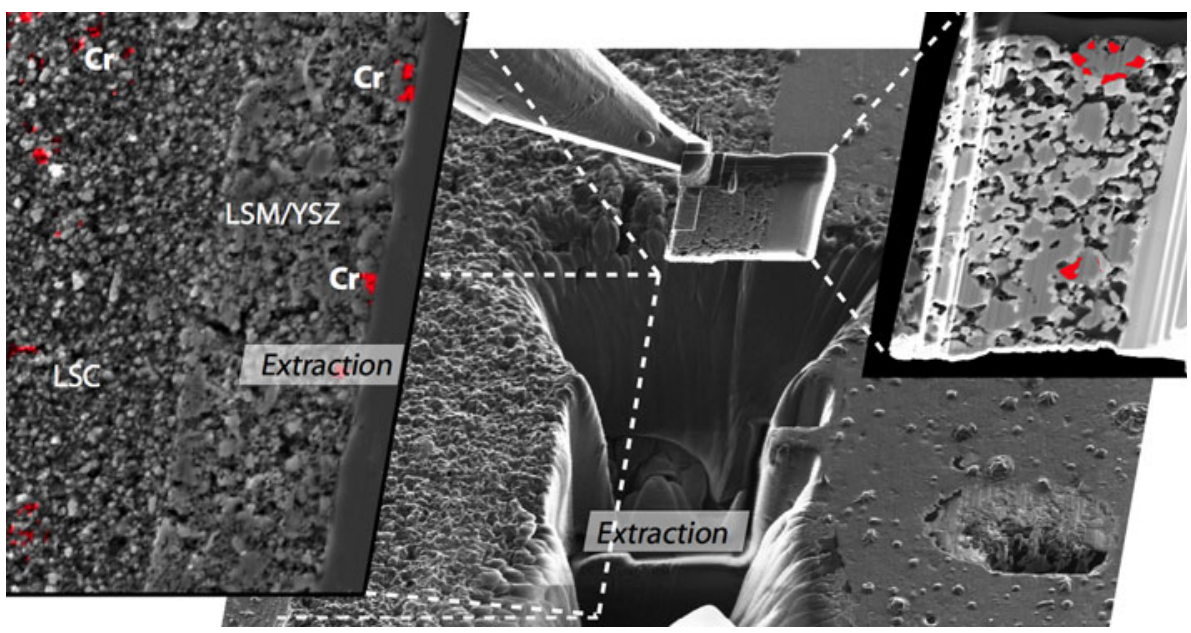

At the LSM/YSZ interface, EDS mapping and spectra reveal the presence of a new phase, indicative of strontium zirconate (SZO). When the electron probe could be placed accurately on this phase (to exclude other phase superposition in the TEM lamella thickness direction), the measured composition was 20.4 at \% Sr, 19.4 at \% $\mathrm{Zr}$ and the balance of oxygen, which corresponds well to the phase $\mathrm{SrZrO}_{3}$.

Several EDS mappings performed on different areas revealed that SZO, when present, is always formed at the YSZ/LSM interfaces. A quantitative line scan was performed across the SZO/LSM interface, indicated by the arrow on Fig. 4, with a $2 \mathrm{~nm}$ probe. A small amount of silicon (between 1.5 and 2.75 at \%) was detected at or near LSM/YSZ interfaces, or at pore borders. Silicon has also been observed in higher quantity (up to 6.5 at \%) at LSM/ YSZ and SZO/LSM interfaces, however, the quantitative

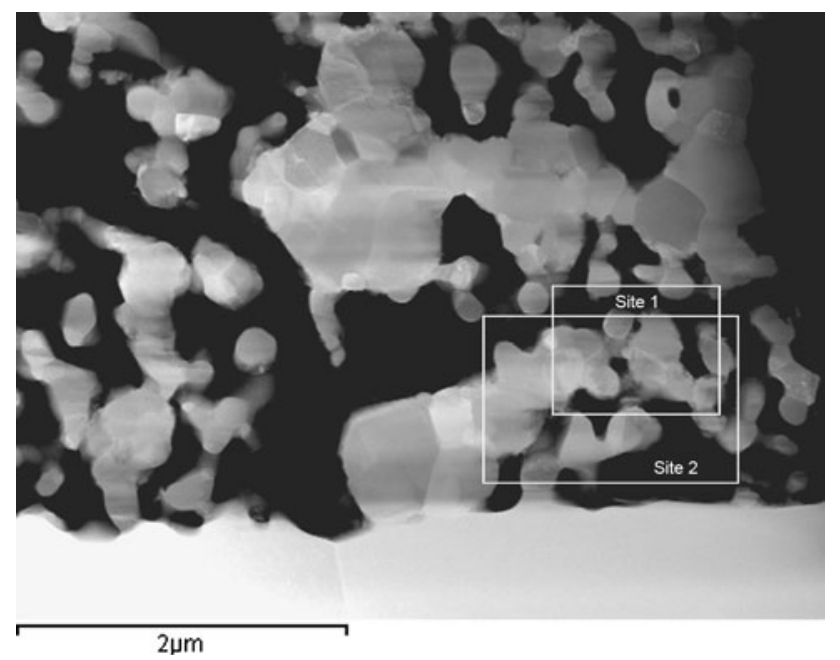

Fig. 3 DSTEM micrograph of the unpolarized segment. The electrolyte is at the bottom, and white squares (site 1 and 2) indicate the two regions of detailed analysis presented in Figs. 4 and 5, respectively measurements contain always two phase superpositions (see Fig. 5), the interfaces not being oriented along the electron beam. Therefore, it is possible that $\mathrm{Si}$ is combined to $\mathrm{Zr}$ and/or $\mathrm{La}$ as silicate phases. The observations do not yet allow to establish the nature of the $\mathrm{Si}$ compound(s) formed; further quantitative investigation is required, as well as its role in cathode degradation.

A micrograph of the polarized segment (Fig. 6) shows microstructural changes compared to the unpolarized segment, as expected from the comparison of impedance spectra. In particular, LSM grains coarsened under polarization. It also appears clearly that the adhesion between LSM and YSZ grains was altered.

Most of the time, though not always, a 20-50 nm SZO layer was found at these delaminated interfaces, as shown by the EDS mapping of Figs. 7 and 8. When SZO is present, delamination always occurs at the SZO/YSZ interface. Further electron diffraction studies and/or higher resolution TEM would enable to determine whether SZO is in epitaxy with the LSM grain or with YSZ, as observed for LZO $[3,6]$.

Cr presence could be located in this polarized segment as a 4-5 nm thin layer of chromium oxide of presumably $\mathrm{Cr}_{2} \mathrm{O}_{3}$, located at the SZO surface before delamination. In Fig. 8, the $\mathrm{Cr}$ layer is indicated by the arrows. Owing to overlap between $\mathrm{Cr}$, Mn and La emission lines, $\mathrm{Cr}$ map contains contribution in the upper part that is presumably due to LSM and not to $\mathrm{Cr}$. In the same sample, $\mathrm{Cr}$ has also been found in combination with sulphur and strontium, and electron diffraction pattern indexing identified it as strontium chromate with sulphur (determined as $\operatorname{Sr}\left(\mathrm{Cr}_{0.85} \mathrm{~S}_{0.15}\right) \mathrm{O}_{4}$ in a previous paper) [24].

In another area, $\mathrm{Cr}_{2} \mathrm{O}_{3}$ has been located at the interface between two LSM grains and the electrolyte. In both cases where $\mathrm{Cr}$ was detected, it was not located at triple phase boundaries, where it would be expected as it is supposed to be responsible for electrochemical activity decrease. 
Fig. 4 TEM micrographs and EDS mapping of LSM/YSZ interface, site 1 of Fig. 3. Green $\mathrm{La}$, blue $\mathrm{Mn}$, grey $\mathrm{Zr}$, orange $\mathrm{Sr}$ and purple $\mathrm{Si}$. The rectangle on the electron micrograph indicates the region considered for the mapping

Fig. 5 TEM micrographs and EDS mapping of LSM/YSZ interface, site 2 of Fig. 3. Green $\mathrm{La}$, blue $\mathrm{Mn}$, grey $\mathrm{Zr}$, orange $\mathrm{Sr}$ and purple $\mathrm{Si}$. The rectangle on the electron micrograph indicates the region considered for the mapping
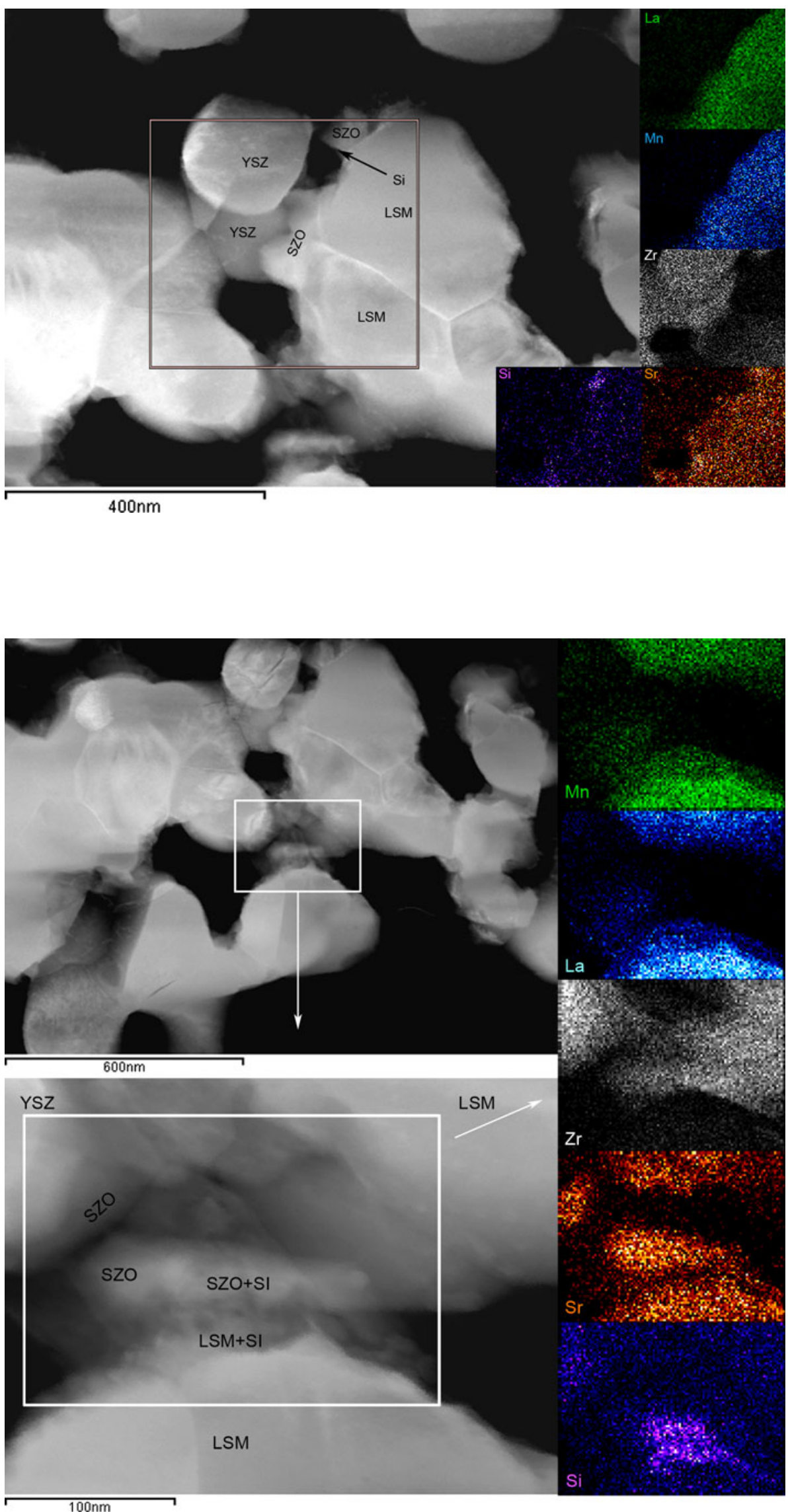


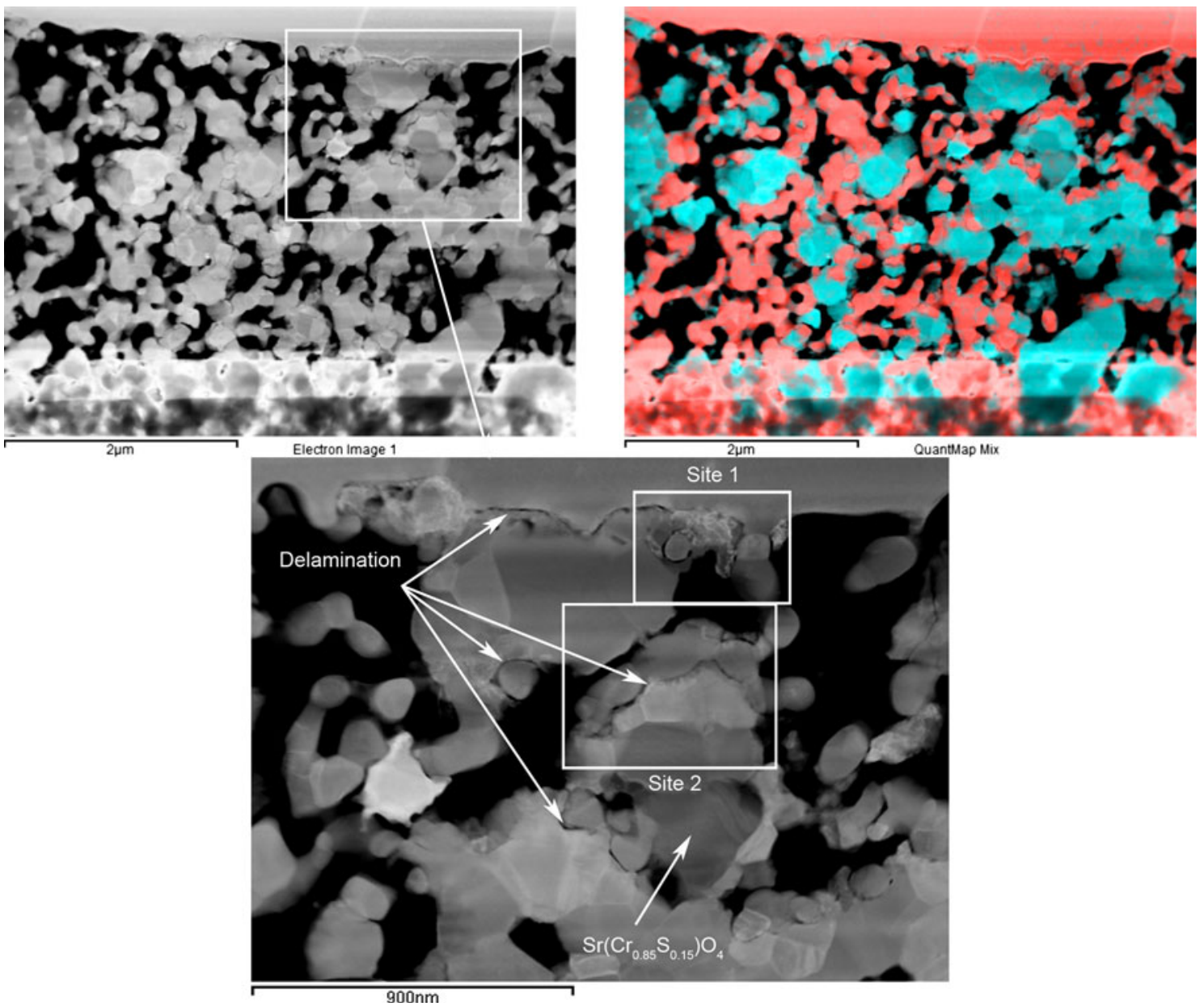

Fig. 6 Overview of a TEM lamella extracted from the polarized segment, with the electrolyte on top. Left DSTEM micrograph. Right EDS mapping of the thin region, with YSZ in red and LSM in blue.
Bottom higher magnification of the region of interest, with delaminations indicated by the arrows, together with sites 1 and 2 as regions for EDS analysis of Figs. 7 and 8, respectively

Fig. 7 TEM micrographs and corresponding EDS mapping of LSM/YSZ interface, site 1 of Fig. 6. Green La, blue Mn, grey $\mathrm{Zr}$ and orange $\mathrm{Sr}$

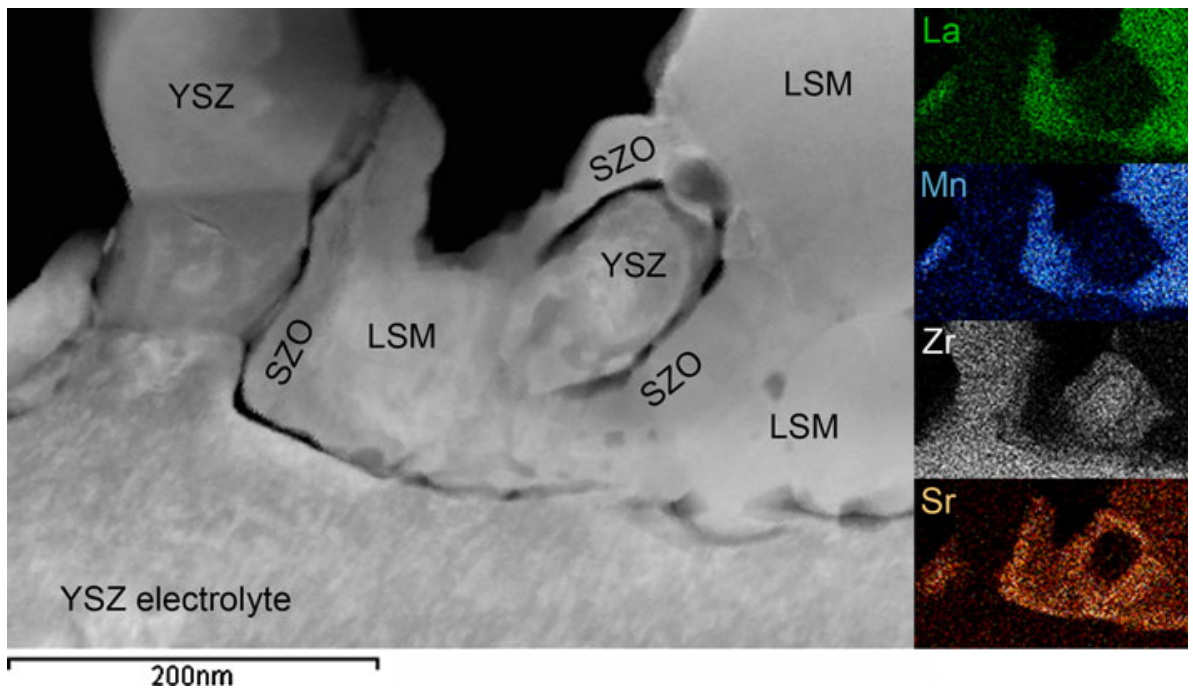

Delamination could be considered as creation of new pores and new TPB, making the reaction possible, and this might explain the location of $\mathrm{Cr}$ deposition. Questions remain about the sequence of $\mathrm{Cr}$ deposition, SZO formation and delamination; a full model explaining all phenomena is at present not established. 
Fig. 8 Element mapping of LSM/YSZ interface. Green La, blue $\mathrm{Mn}$, grey $\mathrm{Zr}$, orange $\mathrm{Sr}$ and purple $\mathrm{Cr}$. The rectangle on the electron micrograph indicates the region considered for the mapping

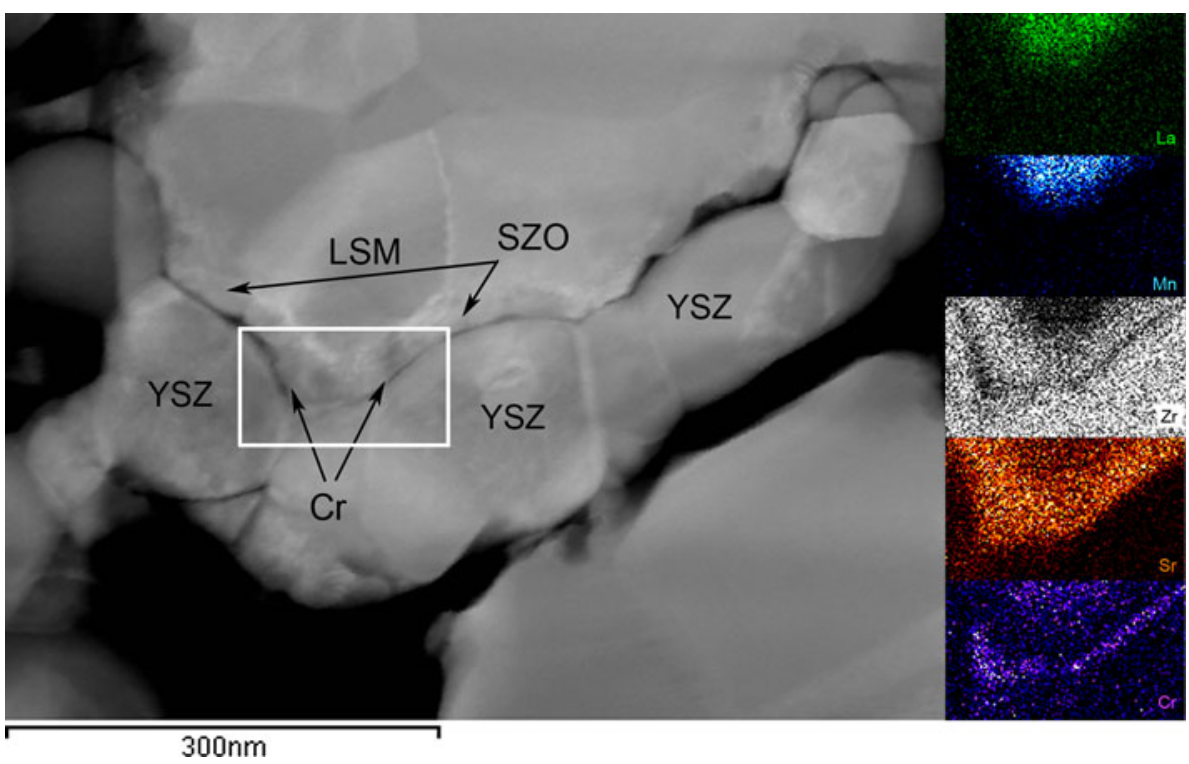

It is confirmed here that $\mathrm{Cr}$ does appear within the active region of the cathode (also shown by SEM observations over the whole cathode thickness elsewhere [24]), but this only on the polarized segment. Its role in cathode deactivation requires further investigations together with the secondary phase formation (SZO). In both the polarized and unpolarized samples, LZO has not been observed; which does not rule out its existence entirely due to the very small sample volumes studied by TEM. Nevertheless, the LZO absence would be consistent with the temperature and $p\left(\mathrm{O}_{2}\right)$ conditions used for the test, according to the values reported in the literature [7]. Finally, the effect of polarization on the morphology of the inter-grain interfaces is clearly visible, confirming the indication obtained by EIS, but the reason why it induces phase delamination is not fully understood yet.

\section{Conclusion}

Secondary phase formation at the cathode/electrolyte interface and cathode $\mathrm{Cr}$ poisoning have been investigated by TEM + EDS in two lamella samples extracted from a segmented repeat element, operated for $1900 \mathrm{~h}$ at $800{ }^{\circ} \mathrm{C}$ in SOFC stack configuration. Strontium zirconate presence has been evidenced and localized at the LSM/YSZ interfaces; no lanthanum zirconate could be found in the examined zones. Significant Si deposits have been found at some LSM/YSZ and SZO/LSM interfaces. Cr has been observed in the polarized segment only, in particular as few nanometre thin $\mathrm{Cr}$ oxide layers localized at the SZO/YSZ interface. Delamination of the LSM/YSZ interfaces was seen to be recurrent in the polarized sample, often accompanied with SZO located at the LSM side. In addition to XRD, SEM-EDX and related techniques, it is illustrated that TEM, when knowing where to look, can offer additional information towards understanding of SOFC degradation behaviour on a scale not detected or suspected by the other methods. In this case, the segmented test rig giving localized results correlated with degradation processes identified by other means (impedance spectroscopy, SEM-EDS), guided us to select the most interesting zones for higher resolution examination by TEM.

Acknowledgements The authors would like to thank the European Commission (FP6 contract SES6-019875.Flame-SOFC) and the Swiss Federal Office for Energy (OFEN, AccelenT project) for financial support, and Fabienne Bobard from CIME for the TEM lamella extraction by FIB.

\section{References}

1. Yokokawa H, Tu H, Iwanschitz B, Mai A (2008) J Power Sour 182(2):400

2. Adler SB (2004) Chem Rev 104(10):4791

3. Chen A, Bourne G, Siebein K, Dehoff R, Wachsman E, Jones K (2008) J Am Ceram Soc 91(8):2670

4. Baukal W, Kuhn W, Kleinschmager H, Rohr FJ (1976) J Power Sour 1(2):203

5. Yamamoto O, Takeda Y, Kanno R, Noda M (1987) Solid State Ion 22(2-3):241

6. Mitterdorfer A, Gauckler LJ (1998) Solid State Ion 111(3-4):185

7. Liu YL, Hagen A, Barfod R, Chen M, Wang HJ, Poulsen FW, Hendriksen PV (2009) Solid State Ion 180(23-25):1298

8. Chen M, Liu YL, Hagen A, Hendriksen PV, Poulsen FW (2009) Fuel Cell 9(6):833

9. Badwal SPS, Deller R, Foger K, Ramprakash Y, Zhang JP (1997) Solid State Ion 99(3-4):297

10. Paulson SC, Birss VI (2004) J Electrochem Soc 151(11):A1954

11. Menzler NH, Batfalsky P, Blum L, Bram M, Groß SM, Haanappel VAC, Malzbender J, Shemet V, Steinbrech RW, Vinke I (2007) Fuel Cell 7(5):356 
12. Chen X, Zhang L, Jiang SP (2008) J Electrochem Soc 155(11):B1085

13. Jiang SP, Zhen Y (2008) Solid State Ion 179(27-32):1459

14. Wang K, Fergus JW (2008) Electrochem Solid-State Lett 11(8):B156

15. Bentzen JJ, H $\sqrt{ } \prod$ gh JVT, Barfod R, Hagen A (2009) Fuel Cell $9(6): 823$

16. Wang K, Fergus JW (2010) J Electrochem Soc 157(7):B1008

17. Sun C, Hui R, Roller J (2010) J Solid State Electrochem 14(7): 1125

18. Chen X, Zhen Y, Li J, Jiang SP (2010) Int J Hydrogen Energy 35(6):2477

19. Liu DJ, Almer J, Cruse T (2010) J Electrochem Soc 157(5):B719

20. Setoguchi $\mathrm{T}$, Inoue $\mathrm{T}$, Takebe $\mathrm{H}$, Eguchi $\mathrm{K}$, Morinaga $\mathrm{K}$, Arai $\mathrm{H}$ (1990) Solid State Ion 37(2-3):217

21. Stochniol G, Broel S, Naoumidis A, Nickel H (1996) Fresenius' J Anal Chem 355(5-6):697

22. Cortés-Escobedo CA, Munoz-Saldana J, Bolarin-Miro AM, Sanchez-de Jesus F (2008) J Power Sour 180(1):209
23. Taniguchi S, Kadowaki M, Kawamura H, Yasuo T, Akiyama Y, Miyake Y, Saitoh T (1995) J Power Sour 55(1):73

24. Schuler JA, Wuillemin Z, Hessler-Wyser A, Van herle J (2009) ECS Trans 25(2): 2845

25. Yokokawa H, Horita T, Sakai N, Yamaji K, Brito ME, Xiong YP, Kishimoto H (2006) Solid State Ion 177(35-36):3193

26. Konysheva E, Mertens J, Penkalla H, Singheiser L, Hilpert K (2007) J Electrochem Soc 154(12):B1252

27. Jiang SP, Zhang S, Zhen YD (2006) J Electrochem Soc 153(1):A127

28. Salvador PA, Wang S, Wilson L, Krumpelt M, Cruse TA (2007) Office of fossible energy fuel cell program

29. Wuillemin Z, Nakajo A, Müller A, Schuler JA, Diethelm S, Van herle J, Favrat D (2009) ECS Trans 25(2):457

30. Wuillemin Z (2009). PhD Thesis $n^{\circ} 4525$, Ecole Polytechnique Fédérale de Lausanne, Lausanne

31. Schuler JA, Tanasini P, Hessler-Wyser A, Van herle J (2010) Scripta Mater 63(8):895 